\title{
APPLICATION OF MOLECULAR TECHNIQUES IN DIAGNOSIS OFTHEILERIOSIS OF CATTLE AND CAMELS IN COMPARISON WITH CONVENTIONAL METHODS IN BEHERA GOVERNORATE
}

\author{
NASHAWA M. HALMY ${ }^{1}$ and REDA S. FADLY ${ }^{2}$ \\ ${ }^{1}$ Department of Biotechnology, Animal Health Research Institute, Dokki, Giza. \\ ${ }^{2}$ Department of Parasitology, Animal Health Research Institute, Dokki, Giza.
}

Received: 29 February 2016; Accepted: 27 April 2016

\begin{abstract}
This study was carried out to determine the rate of Theileria infection in cattle and camels in Behera governorate by microscopic examination, confirm and identify the species by polymerase chain reaction (PCR). The prevalence of Theileria infection in cattle and camels was $20 \%(15 / 75)$ and $28 \%(21 / 75)$ respectively, by microscopic examination (ME) of blood smears. Five positive samples by ME (3camels and 2 cattle) in addition, four negative samples were subjected to semi-nested PCR. The PCR result (6 out of 9) examined blood samples (4 camels and 2 cattle) were PCR positive using Theileria species specific primer at 430bp. All positive samples for Theileria sp. Using Tbs-S/Tbs-A primers were used as a template and amplified by using Ta-S/ Tbs-A primers specific for Theileria annulata. All examined samples (6/6), 2 from cattle and 4 from camels were positive for Theileria annulata at $193 \mathrm{bp}$. In conclusion, the PCR especially semi-nested PCR (snPCR) are highly specific and sensitive methods for identifying the species of Theileria annulata and screening the carrier cattle and camels in the epidemiological surveys. On the other hand, Giemsa staining method is not suitable for detecting the carrier or chronic phases of theileriosis, although it is an easy and fast diagnostic technique for detecting this infection in acute phase with clinical signs.
\end{abstract}

Key words: Camels, cattle, Theileriosis, Blood smears, Semi-nested PCR.

\section{INTRODUCTION}

Theileriosis is one of the most common tickborne diseases, which have been studied and described in a wide range of ruminants such as cattle, sheep, and goats. In camels, only few literatures were published (El-Refaii et al., 1998; El Kammah et al., 2001 and El-Fayoumy et al., 2005). Theileria are tick-transmitted, obligate intracellular parasites that are important pathogens of livestock in the tropical and subtropical regions of the world. Hyalomma spp. (H.spp.), especially Hyalommadromedarii and Hyalommaannatolicum excavatum are the common ticks infesting camels in Egypt (Abd El-Baky 2001). The disease threatens estimated 250 million cattle and acts as a major constraint on livestock production and improvement in many developing countries. Theileria parasites enter the bovine host during tick feeding as sporozoites, which rapidly invade mononuclear leukocytes. Here, they mature into macroschizonts and induce proliferation of the host cell.

Corresponding author: Dr. REDA S. FADLY

E-mail address: dr_redafadly@yahoo.com

Present address: Department of Parasitology, Animal Health Research Institute, Dokki, Giza.
Macroschizonts develop further into microschizonts and ultimately into merozoites, which are released from the lymphocyte. The merozoites invade erythrocytes and develop into piroplasms. Tropical theileriosis is a lymph proliferative disease in its early phases and is accompanied by enlargement of lymph nodes. On development of pyrexia, a lymphdestructive phase which is associated with a pronounced leukopenia is initiated. The disease is further characterized by a marked anemia. Diagnosis of clinical $T$. annulata infection in cattle is usually based on the detection of macroschizonts in Giemsastainedlymph node biopsy smears. After recovery, a long-lasting carrier state occurs, in which low numbers of erythrocytes remain infected with Theileria piroplasms. Such carriers are important contributes to the infection within Hyalomma Ticks. Hence, detection of piroplasms in carrier animals is an important epidemiological parameter. However, Theileria piroplasms may be difficult to find in stained blood smears. More important, it is generally not possible to discriminate $T$. annulata from nonpathogenic Theileria species that may occur simultaneously within the same bovine host. Diagnosis of the disease based on microscopic examination of Giemsa stained blood smears and lymph node biopsy is disadvantageous in case of low 
parasitemia and carrier state animals (Kundave et al., 2014 and Khatoon et al., 2015). However, the molecular based assays such as PCR have proven to be the most reliable tool for detecting Theileria parasites in clinicaland subclinical cases of theileriosis (Aktas et al., 2006 and Khatoon et al., 2015).

The aim of this study is to confirm and identify the Theileria sp. infecting cattle and camels by using polymerase chain reaction (PCR) in comparison to microscopic examination of thin blood.

\section{MATERIALS AND METHODS}

\section{Samples:}

A total of 150 blood samples on anticoagulant (EDTA) were collected cattle (75) and camels( 75). Samples were collected from different localities in Behera Governorate.

\section{Microscopic examination:}

Thin blood smears were prepared immediately after drawing the blood samples, fixed with methanol, stained with Giemsa and examined by light microscopy at 1000x magnification as described by (Coles, 1986). The stained blood smears were examined for Theileria piroplasms and schizonts as described by (Kelly, 1979). Each blood smear was examined twice before being considered negative.

\section{Samples for PCR:}

Nine blood samples divided into five positive samples for Theileria infection ( 2 from cattle and 3 from camels) and four negative samples for Theileria infection ( 2 from cattle and 2 from camels) were subjected to PCR using Theileria species specific primer.

DNA extraction from whole blood samples

DNA was extracted from whole blood samples by using Thermo scientific kits (Gene JET Genomic DNA Purification Kit \#K0721, \#K0722).

\section{Oligonucleotide primers:}

For conventional PCR, two set of oligonucleotide primers were synthesized and designed Tbs-A/ Tbs-S. and Tbs-A/ Ta-S according to (Hoghooghi et al., 2011). The sequences of primers used in this study are listed in the Tbs-S/Tbs-A primer set was used for PCR amplification of 18SrRNA of Theileria sp. and the amplified sequence weight by this primer set for Theileria sp. was 426-430 bp. The amplified product of all PCR positive samples for Theileria species using Tbs-S/Tbs-A primers were used as a template and amplified by using Ta-S/Tbs-A primers. The Ta$\mathrm{S} / \mathrm{Tbs}-\mathrm{A}$ primer set derived from the 18SrRNA encoding gene specific for Theileria annulata. The amplified sequence by this specific primer set was $193 \mathrm{bp}$.

\section{Polymerase chain reaction}

DNA amplification was done in 25 ul reaction volume containing 12.5 ul of $2 \times$ Taq PCR Master Mix (Tiangen, Cat No. Cat. no. KT201), 10 pmol of each oligonucleotide primers Tbs-S/Tbs-A, 5 ul of DNA template and fill up to $25 \mathrm{ul}$ with DNA se and RNA se free water. The reaction was performedin an automatic DNA Thermo cycler (Biometra) with the following program: $5 \mathrm{~min}$ incubation at $95^{\circ} \mathrm{C}$ to denature double strand DNA, 34 cycles of $45 \mathrm{~s}$ at $94^{\circ} \mathrm{C}, 90 \mathrm{~s}$ at $55^{\circ} \mathrm{C}, 45 \mathrm{~s}$ at $72^{\circ} \mathrm{C}$ and finally, PCR was completed with the additional extension step for 5 min. Samples were considered positive for species when a single band of DNA at 426- 430 bp, was evident in the ethidium bromide stained gels, compared with the molecular size marker (100bp DNA ladder.

\section{Semi-nested PCR (snPCR)}

In order to show that the Tbs-S/Tbs-A PCR product was Theileria annulata, it was amplified in $25 \mathrm{ul}$ reaction volume containing 12.5 ul of $2 \times$ Taq PCR Master Mix for PCR (Tiangen, Cat No. Cat. no. KT201), 10 pmol of each oligonucleotide primers Ta$\mathrm{S} / \mathrm{Tbs}-\mathrm{A}$ primer, $5 \mathrm{ul}$ of the first PCR amplicon as template and fill up to 25 ul with DNAse and RNAse free water. The optimized cycle program for the second PCR was $5 \mathrm{~min}$ at $95 \mathrm{C}$ to denature double strand DNA, Two cycle of $94^{\circ} \mathrm{C}$ for $45 \mathrm{~s} .55^{\circ} \mathrm{C}$ for 90 sand $45 \mathrm{~s}$ in $72^{\circ} \mathrm{C}$. followed by 35 cycles of $45 \mathrm{~s}$ at $94^{\circ} \mathrm{C}, 45 \mathrm{~s}$ at $55^{\circ} \mathrm{C}$ and $72^{\circ} \mathrm{C}$ for $45 \mathrm{~s}$. Finally, Seminested PCR (snPCR) was completed with the additional extension step at $72^{\circ} \mathrm{C}$ for $5 \mathrm{~min}$. according to (Hoghooghi et al., 2011).

\section{Electrophoresis of $\mathrm{PCR}$ product:}

After amplification $10 \mathrm{ul}$ of the reaction product was mixed with 2 ul of $6 \mathrm{X}$ gel loading dye and subjected to electrophoresis on $1.5 \%$ agarose gel in TBE buffer (Tris, Boric acid, EDTA buffer) at $100 \mathrm{~V}$ for $30 \mathrm{~min}$. Gel were stained with ethidium bromide and photographed on UV trans illuminator. Samples were considered positive for Theileria species by using Tbs-S/Tbs-A primers and positive for Theileria annulata by using Ta-S/Tbs-A when a single band of DNA at 426-430 bp and $193 \mathrm{bp}$ respectively were evident in the ethidium bromide stained gels, compared with the molecular size marker (100 bp DNA ladder, Jena Bioscience Cat. No. M-214) as shown in (Fig 6) and (50 bp DNA ladder, Gene Dire $\mathrm{X}$ Cat. No. DMO12-R 500) as shown in (Fig 7).

\section{RESULTS}

\section{Microscopical examination:}

Blood smears showed that, overall, the prevalence of Theileria infection in cattle and camels was recorded as $20 \%$ and $28 \%$ respectively (Table 2 ). The stained blood films revealed the presence of ring forms of Theileria were found in erythrocytes of cattle (Fig 1), 
camel (Fig 5) and schizonts were detected in the lymphocytes with two forms (macro and micro) stages were detected in blood smears of both cattle and camels (Figs. 2,3 and 4).

\section{PCR results:}

(Table 3): Showed that, all samples proved to be positive by thin blood smears examination were also positive by (snPCR) after using Theileria species specific primer. Whereas, only one camel sample was negative by microscopical examinations were proved to be positive by (snPCR). Six out of nine blood samples (2cattle and 4 camels) were PCR positive using Theileria species specific primer at $430 \mathrm{bp}$ (Fig.6). All 6 positive samples for theileria species by PCR were amplified by semi nested PCR with Theileria annulata specific primer at 193 bp. (Fig. 7).

Table 1: Oligonucleotide primer sequences specific for Theileria sp. and Theileria annulata.

\begin{tabular}{|c|c|c|c|c|}
\hline \multirow{2}{*}{$\begin{array}{c}\begin{array}{c}\text { Theileria sp. } \\
\text { primer }\end{array} \\
\text { Tbs-A }\end{array}$} & Gene & Nucleotide sequences $\left(5^{\prime}-3^{\prime}\right)$ & \multirow[t]{2}{*}{$\begin{array}{c}\text { Amplified } \\
\text { product }\end{array}$} & \multirow[b]{2}{*}{$\begin{array}{l}\text { (Hoghooghi, } \\
\text { et al., 2011). }\end{array}$} \\
\hline & 18S rRNA & 5-'CTA AGA ATT TCA CCT CTG ACA G-3' & & \\
\hline Tbs-S & 18S rRNA & 5'-CAC AGG GAG GTA GTG ACA AG-3' & $430 \mathrm{pb}$ & $\begin{array}{l}\text { (Hoghooghi, } \\
\text { et al., 2011). }\end{array}$ \\
\hline Ta-S & 18S rRNA & 5-ACG GAG TTT CTT TGT CTG-3' & 193 bp & $\begin{array}{l}\text { (Hoghooghi, } \\
\text { et al., 2011). }\end{array}$ \\
\hline Anim & & No.ofanimal & & $\%$ \\
\hline catt & & 15 & & 20 \\
\hline cam & & 21 & & 28 \\
\hline
\end{tabular}

Table 3: The results of PCR in comparison with microscopical examination (ME).

\begin{tabular}{|c|c|c|c|c|}
\hline \multirow{2}{*}{$\begin{array}{l}\text { No. of } \\
\text { animal }\end{array}$} & \multirow[t]{2}{*}{ Animals } & \multirow[t]{2}{*}{ ME } & \multicolumn{2}{|l|}{ PCR } \\
\hline & & & Theileria species & T.annulata \\
\hline 1 & cattle & + & + & + \\
\hline 2 & cattle & - & - & - \\
\hline 3 & cattle & + & + & + \\
\hline 4 & cattle & - & - & - \\
\hline 5 & camel & - & - & - \\
\hline 6 & camel & + & + & + \\
\hline 7 & camel & + & + & + \\
\hline 8 & camel & + & + & + \\
\hline 9 & camel & - & + & + \\
\hline Total & 9 & 5 & 6 & 6 \\
\hline
\end{tabular}




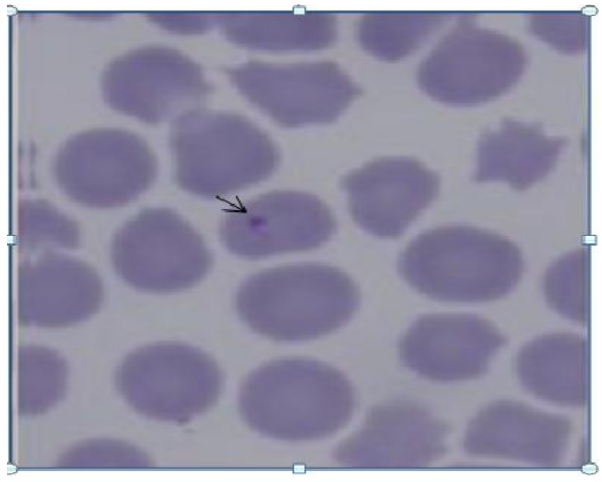

Fig. (1): Gimsa stained blood smear in Cattle Showing intra -erythrocytic piroplasms of T. annulata (X 1000).

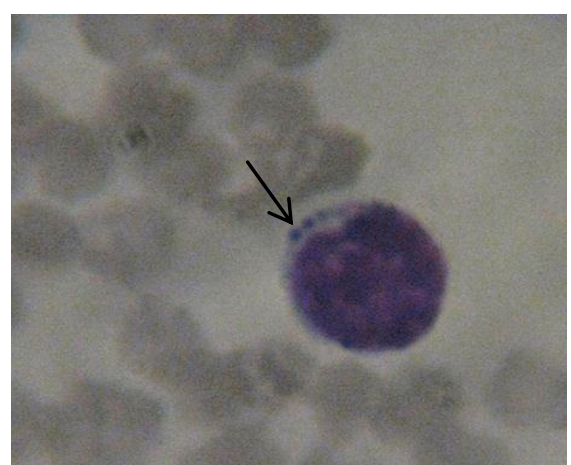

Fig. (2): Gimsa stained blood smear macro schizonts (X 1000)

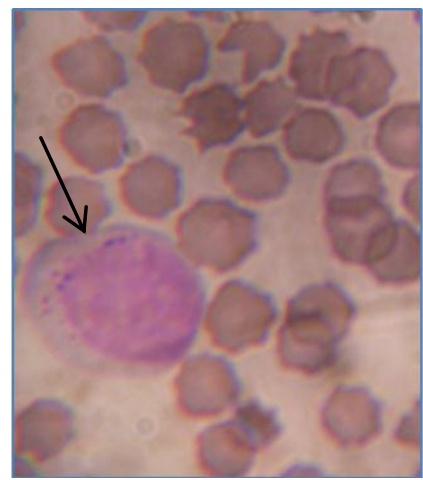

Fig. (3): Gimsa stained blood smearmicroschizonts in cattle (X 1000)

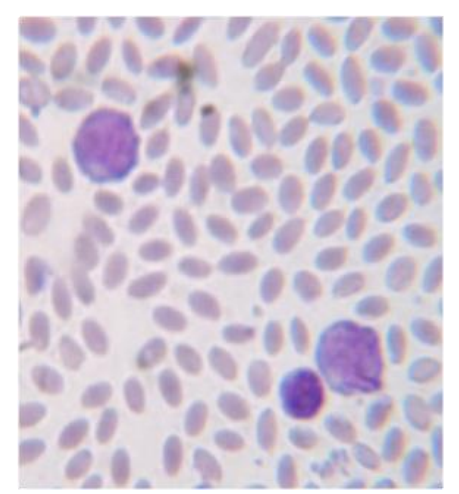

Fig. (4): Gimsa stained blood Smear macro \& microschizonts in camel (X 1000)

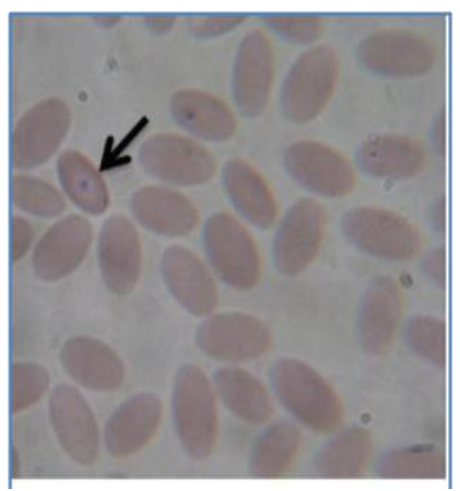

Fig. (5): Gimsa stained blood smear showing ring form of $T$. annulata in camel (X 1000)

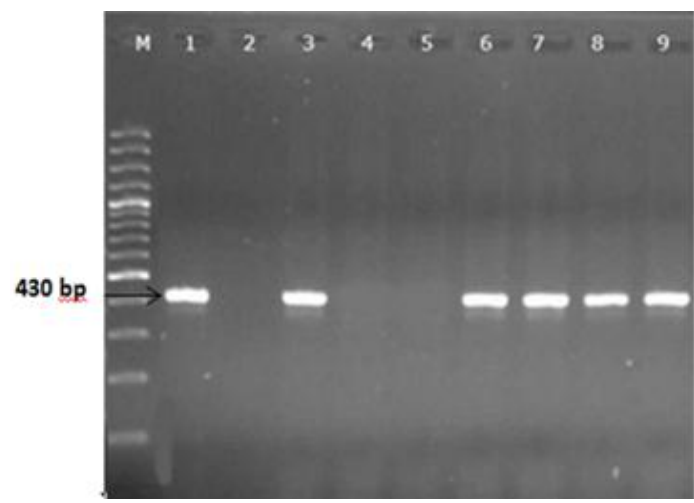

Fig. (6): Ethidium bromide stained 1.5\% agarose gel electrophoresis showed PCR amplified fragment of expected size $430 \mathrm{bp}$ (Lane 1, 3,6,7,8,9) resulted from amplification of DNA extracted from blood samples of cattle (1-4) and camel (5-9) using Tbs- S /Tbs-A primers specific to Theileria spp. Lane M : 100 marker, Jena Bioscience.

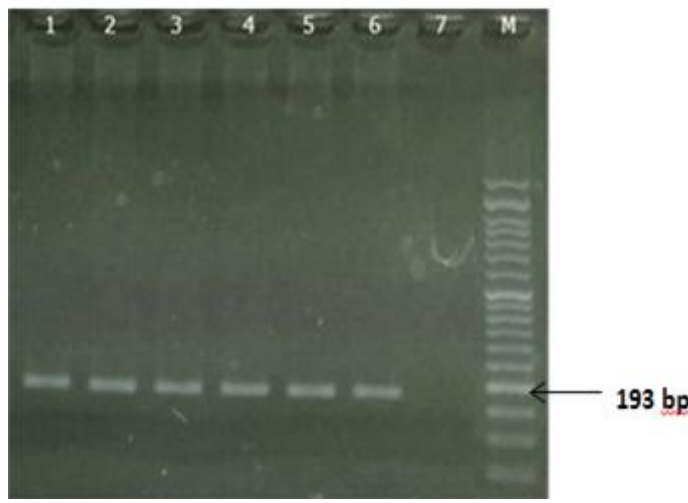

Fig. (7): Ethidium bromide stained 1.5\% agarose gel electrophoresis showed PCR amplified fragment of expected size 193 bplane 1-2 contained PCR products from cattle and (lane3-6) contained PCR products from camel resulted from amplification of the first PCR amplicon using Ta-S /Tbs-A primers specific to Theileria annulata Lane M:50 bp marker, Gene Dire X. 


\section{DISCUSSION}

Theileriosis is an important parasitic disease of cattle and camels in Egypt which causes great economic losses of animals and their products (Al-Gaabary, 1995 and AL-Hosary, 2009). In the present study Theileria spp. was $20 \%$ in cattle by Giemsa stain blood films (Table 2), this result was relatively similar to Reda (2012) in Behera Province was $23 \%$ and Acici (1995) in Turkey was $17 \%$ lower prevalence rates reported by Adel (2007) in Gharbia Governorate was $11.31 \%$ and El Bader et al. (2009) in Southvally was $10.3 \%$. However higher prevalence rates were reported in Egypt, among them El Bahy (1986), who revealed that prevalence rates was $65 \%$, Gamal El Dien (1993) in Behera province, who found that the prevalence of $T$. annulata was $65.4 \%$ using stained blood films and Hosny et al. (2010) in Assiut Governorate whose recorded that the incidence of theileriosis among cattle was $31.58 \%$. Variation in prevalence rates could possibly be attributed toan abundance of the vectors as a result of high temperature and humidity, age groups evaluated, sample size and health condition of animal.

In the present study the prevalence of Theileria infection in one-humped camel was detected at rate of $28 \%$ by microscopic examination of blood smears for Theileria sp. Similar result recorded by Shereen et al. (2015) who recorded that the incidence of theileriosis among camels were $(30.86 \%)$ in Egypt. While our result lower that detected by El-Refaii et al. (1998); El-Fayoumy et al. (2005) and Abd El-Wahab (2009) were $62.1,44.8$ and $44.23 \%$ respectively. On the other hand lower percentage of infection reported by Azizi et al. (2008); Maha et al. (2011) and Osman et al. (2015) who recorded that the incidence of theileriosis among camels were $8.1 \%, 6.75 \%$ and $9 \%$ respectively. These variations in the different results may be attributed to different localities, population density of camels, environment, hygienic measures, as well as the age variation of examined animals and camel management.

It is imperative to develop sensitive tools for the effective diagnosis of theileriosis in order to reduce the economic losses incurred as result of the disease. A number of conventional and modern techniques are used for the detection of Theileria spp. in host animals. The most commonly used is the microscopic examination of blood smears stained by Giemsa, which is typically adequate for detection of acute infections. Due to its low sensitivity, this technique cannot be used for the detection of carrier animals due to low parasitemia. Serological tests have several disadvantages like the presence of antibodies for long period even after treatment and cross-reactivity (Leemans et al., 1999). The use of molecular methods (such as PCR) for the detection and identification of different microorganisms has gained popularity among scientists in recent years. This is because molecular methods are more specific and sensitive than other traditional diagnostic techniques (Altay et al., 2005).

Concerning to PCR assay, this study showed that complete concordance between microscopical examination and PCR assay results in cattle, while in camel PCR results don't coincide with microscopical examination Whereas, one camel blood sample was negative by microscopical examinations were proved to be positive by PCR (Table 3), six cases were positive for Theileria sp. Two of cattle and four of camels were positive for Theileria species at $430 \mathrm{bp}$ using Tbs-S/Tbs-A derived from 18srRNA encoding gene and they were amplified by semi-nested PCR with Theileria annulata specific primer set (TaS/Tbs-A) derived from 18srRNA encoding gene and they were positive for Theileria annulata and give $193 \mathrm{bp}$. These results especially in camels may be due to microscopical examinations does not detect positive animals in the early stage of infection and the long-term carrier status, conditions in which parasitemia is very low. Results are in agreement with a previous report on $T$. annulata (Hoghooghi et al., 2011). Our results demonstrate that this PCR assay discriminate $T$. annulata from non-pathogenic Theileria species. The result of this study coincided with (Abd El-Wahab, 2009 and Randa et al., 2014) which mentioned that the PCR assays are more sensitive and specific than conventional diagnostic techniques in the diagnosis only few literatures were published. Also Hoghooghi et al. (2011) reported that Semi-nested PCR based on detecting Theileria annulata, was capable of showing the cases which their Giemsa stained blood smears were false negative or false positive in visual examination under light microscope.

\section{CONCLUSION}

The PCR especially semi-nested PCR are highly specific and sensitive methods for identifying the species of Theileria annulata from non-pathogenic Theileria species. PCR technique being used as confirmatory test with microscopical examination especially on endemic area. On the other hand, Giemsa staining method is an easy and fast diagnostic technique for detecting Theileria infection in acute phase while not suitable for detecting the carrier or chronic phases of Theileria infection. T.annulata is one of Theileria spp. highly prevalent and potentially a major problem in cattle and camels in Behera Governorate.

\section{REFERENCES}

Abd El-Baky, S.M.M. (2001): Prevalence of external parasites in the south eastern desert of Egypt, Journal Egyptian Society Parasitology, 31, 223-232. 
Abd El-Wahab, A. (2009): Theileria species infecting camels in Egypt: comparison of polymerase chain reaction (PCR) based and light microscopy detection. EVMPJ. 5:71-82.

Acici, M. (1995): Prevalence of blood parasites in cattle in the Sam sun region, Turkey. Etlik Vet. Mikrob Derg 8:271-277.

Adel, E.M. (2007): Studies on some blood parasites infecting farm animals in Gharbia Governorate, Egypt. Ph.D. thesis, Faculty of Veterinary Medicine, Cairo University Cairo, Egypt.

Aktas, M.; Altay, K. and Dumanli, N. (2006): A molecular survey of bovine Theileria parasites among apparently healthy cattle and with a note on the distribution of ticks in eastern Turkey. Vet. Parasitol. 138: 179-85.

Al-Gaabary, M.H. (1995): Epidemiological and immunological studies on bovine tropical theileriosis. Ph.D. Thesis. Department of Animal Medicine, Faculty of Veterinary Medicine, Zagazig University.

AL-Hosary, A.A.T. (2009): Recent methods of diagnosis and trail of treatment of bovine theileriosis. M. Vet. SC. Thesis, Animal Medicine Department (Infectious Diseases), Faculty of Veterinary Medicine, Assiut University.

Altay, K.; Dumanli, N.; Holman, P.J. and Aktas, M. (2005): Detection of Theileria ovis infected sheep by nested PCR. Vet. Parasitol. 127: 99104.

Azizi, H.; Shiran, B.; Farzaneh Dehkordi, A.; Salehi, F. and Taghadosi, C. (2008): Detection of Theileria annulata by PCR and its Comparison with Smear Method in Native Carrier Cows. Biotechnology. 7 (3): 574-577.

Coles, E.H. (1986): Veterinary Clinical Pathology. 4th ed., published by W.B. Saunders Co., Philadelephia.

El Badr, A.; Ibrahim, A.; Tolba, M.; Metwally, A.; Zaghlol, D. and Osman, A. (2009): Piroplasmosis in cattle and buffaloes in south valley Governorates, Egypt. EVMSPJ, 5: 8389.

El Bahy, N.M. (1986): Some studies on ticks and tick borne disease among ruminants in Fayoum Governorate. M.V.Sc. thesis (Parasitology), Faculty of Veterinary Medicine, Cairo University, Cairo, Egypt.

El-Fayoumy, M.M.; Abou Elnga, T.R.; Abd El-Baky, S.M. and Abdou, T.A. (2005): Prevalence and of camel theileriosis and its vector tick in North Coast of Egypt. J. Egypt. Vet. Med. Assoc., 65: 291-302.

El-Refaii, M.A.H.; Wahba, A.A. and Shehab, G.J. (1998): Studies of Theileria infection among slaughtered camels in Egypt. Egypt. J. Med. Sci., 19: 1-17.
Gamal EI-Dien, H.Y. (1993): Studies on Theileria protozoan among cattle in Behera Province. M.V.Sc. thesis, Faculty of Veterinary Medicine, Alexandria University, Alexandria, Egypt.

Hoghooghi, R.N.; Ghaemi, P.; Shayan, P.; Eckertm, B. and Sadr-Shirazi, N. (2011): Detection of Native Carrier Cattle Infected with Theileria annulata by Semi-Nested PCR and Smear Method in Golestan Province of Iran. World Appl. Sci. J.12 (3): 317-323

Hosny, M.A.; Aly, A.S. and Ahmed, O. (2010): Oxidative stress and some Haematobiochemical changes in blood of cattle during theileriosis Assiut. Vet. Med. J., 56: $218-238$.

Kelly, W.R. (1979): Veterinary clinical diagnosis. $2^{\text {nd }}$ Edn., Bailliere Tindall, London, pp: 261-300.

Khatoon, S.; Kolte, S.W.; Kurkure, N.V; Chopde, N.A. and Jahan, A. (2015): Detection of tropical bovine theileriosis by polymerase chain reaction in cattle. J. Parasit Dis.; 39(1): 53-6.

Kundave, V.R.; Patel, A.K.; Patel, P.V.; Hasnani, J.J. and Joshi, C.G. (2014): Qualitative and quantitative assessment of Theileria annulata in cattle and buffaloes Polymerase Chain Reaction. Trop Biomed 31(4): 728-35.

Leemans, I.; Brown, D.; Fossum, C.; Hooshmandrad, P.; Kirvar, E.; Wilkie, G. and Uggla, A. (1999): Infectivity and croos immunity studies of Theileria lestoquardi and Theileria annulata in sheep and cattle. in vivo studies. Vet. Parasitol., 82: 193-204.

Maha, I.H.; Zaitoun, A.A.; El-Allawy, A.T. and Mourad, I.M. (2011): Investigation of Theileria camelensis in camels infested by Hyalomma dromedarii ticks in Upper Egypt. J. Adv. Vet. Res., 1: 4-7.

Osman, F.A.; Nagieb, M.A. and Gaadee, H.I. (2015): Some Studies on Prevalence and Effect of Thieleria Infection on Erythrocytes Profile in Camel in Some Localities at New-Valley, Governorate, Egypt. J. Anim. Sci. Adv., 5(4): 1238-1244.

Randa, A. Hassam; Radwan, I.G.H.; Khadra, M. Soliman and Abbasa, A. (2014): Parasitological and Pathological studies on camels (camelus dromedaries) naturally infected with Theileria species. EVMPJ. 10: 17-31.

Reda S. Fadly (2012): Prevalence of blood parasites of some farm animals at Behera Province, Assiut. Vet. Med. 58 (134): 316-322.

Shereen Y. Youssef; Safaa Yasien; Mousa, W.A.; Soad M. Nasr; El-Kelesh, E.A.; Mahran, K.M. and Azza H. Abd-El-Rahman (2015): Vector identification and clinical, hematological, biochemical, and parasitological characteristics of camel (Camelusdromedarius) theileriosis in Egypt, Trop. Anim. Health Prod 47: 649-656. 


\title{
تطبيق الاختبارات الجزيئية فى تثخيص الثيليريا في الأبقار والإبل بالمقارنة بالطرق التقليدية في محافظة البحيرة
}

\author{
نشوى محمد حلى ، رضا سعير فضلى \\ E-mail: dr_redafadly@yahoo.com Assiut University web-site: www.aun.edu.eg
}

يعتبر مرض ثيليريا الماشيه من أهم الامر اض الأقتصادية التي تصيب الماشيه من جميع السلالات والاعمار ويؤدى الى خسائر

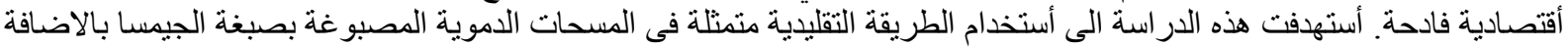

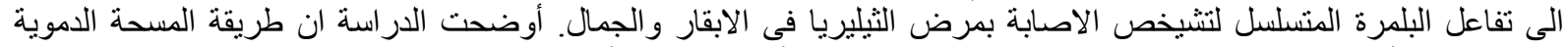

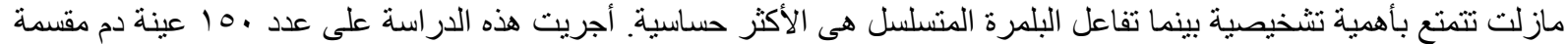

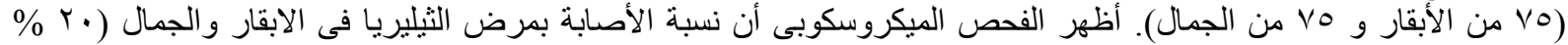

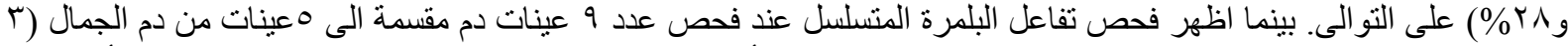

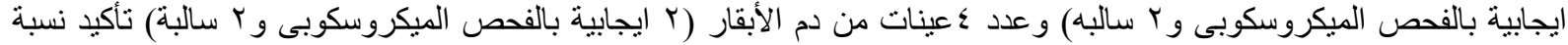

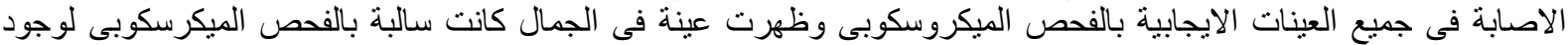

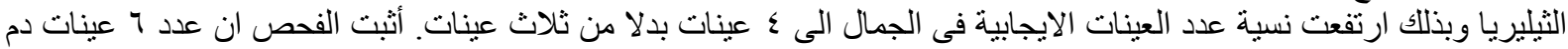

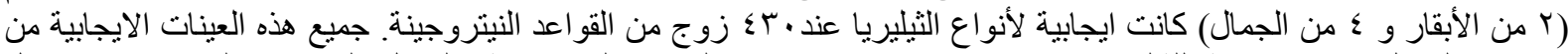

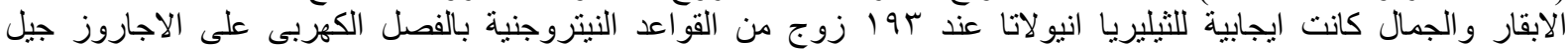
اليكثروفوريسيس. 